\title{
MATEMÁTICA É REALIDADE: ESTRATÉGIAS DE CONTEXTUALIZAÇÃO NA PRÁTICA PEDAGÓGICA
}

\section{ARTIGO DE REVISÃO}

LEITE, Michael Douglas Sousa ${ }^{1}$

COSTA, Kylvia Luciana Pereira ${ }^{2}$

BELCHIOR, Sandra Maijane Soares de ${ }^{3}$

BELCHIOR, Verônica Cristian Soares de ${ }^{4}$

LACERDA, Wendell de Almeida ${ }^{5}$

NASCIMENTO, Rafael Eduardo Inacio do ${ }^{6}$

\footnotetext{
${ }^{1}$ Mestrando em Sistemas Agroindústrias - UFCG, Pós-Graduado em Docência do Ensino Superior, Graduado em Administração - UFCG.

2 Pós-Graduada em Gestão em Saúde - UFRN, Bacharel em Enfermagem - UFCG, Graduanda em Letras - IFPB.

${ }^{3}$ Mestranda em Sistemas Agroindústrias - UFCG, Pós-Graduada em Gestão Econômica e estratégias de Negócios-FIP, Graduada em Ciências Econômicas.

${ }^{4}$ Mestranda em Sistemas Agroindústrias - UFCG, Pós-Graduada em Ciências Políticas da Educação, Graduada em Ciências Econômicas.

${ }^{5}$ Mestre em Sistemas Agroindústrias - UFCG, MBA Auditoria Contábil - FIP, Especialista em Psicopedagogia - FIP, Graduado em Administração.

${ }^{6}$ Mestrando em Sistemas Agroindustriais (UFCG). Mestre em Ciências da Educação (Absoulute Christian University - Mestrado ainda não convalidado no Brasil). Especialista em Direito Tributário (FIP). Bacharel em Ciências Contábeis (UFCG). Licenciando em Matemática (Unopar).
} 
PIRES, Maria José Soares de Belchior ${ }^{7}$

LEITE, Michael Douglas Sousa. Et al. Matemática é realidade: Estratégias de contextualização na Prática Pedagógica. Revista Científica Multidisciplinar Núcleo do Conhecimento. Ano 05, Ed. 09, Vol. 08, pp. 99-115. Setembro de 2020. ISSN: 2448-0959, Link de acesso: https://www.nucleodoconhecimento.com.br/educacao/matematica-erealidade

\section{RESUMO}

A qualidade do ensino da Matemática no Brasil atingiu seu nível mais baixo na história educacional do país. Assim, percebe-se que a educação atual passa por um momento de reflexão acerca das possibilidades de um ensino da Matemática mais significativo, de forma a superar os velhos processos de ensino que não satisfazem às expectativas tanto dos professores como dos alunos no processo ensino aprendizagem. Nesta procura por maneiras novas de ensinar, surgem modismos nos processos metodológicos. Dentre as várias formas novas e antigas de ensinar Matemática, muitas das quais apenas deixam o professor mais confuso, parece ser consenso geral na atualidade, a necessidade de ensinar os conteúdos de forma contextualizada. Nesse sentido, o presente artigo objetou-se analisar o ato de contextualização na docência da Matemática. A estrutura do presente artigo trata-se de um estudo do tipo bibliográfico, utilizando livros, artigos, monografias e manuais. Os resultados mostraram o consenso entre os docentes e pesquisadores, que a Matemática tem sido lecionada de maneira enfadonha. Observou-se, que uma das problemáticas mais enfrentadas, é o grau elevado de antipatia causada por ela, especialmente por causa da ausência de exercícios e problemas que a relacione com o mundo real. Outro fator é que muitos professores desconhecem o real significado da contextualização e assim não sabem utilizá-la. Isto acaba refletindo diretamente no aprendizado, levando os alunos a acreditar que o docente não está ensinando nada e apenas enrolando durante as aulas. O objetivo de utilizar a contextualização, é de poder criar cenários

\footnotetext{
7 Graduada em Serviço Social.
} 
para uma aprendizagem motivadora, que supere o distanciamento entre as experiências do aluno e os conteúdos estudados, estabelecendo relações e trazendo alusões que podem ser de natureza sociocultural ou histórica ou mesmo na própria Matemática.

Palavra-chave: Educação, contextualização, ensino, matemática.

\section{INTRODUÇÃO}

A Matemática está contida em nossas vidas, desde uma simples contagem até o uso em de algoritmos complexos em computadores. Na Economia, por exemplo, tem-se o cálculo de juros simples/compostos e porcentagens; na Engenharia os cálculos trigonométricos; na feira livre os processos básicos de contagem das quatro operações e entre outros. Em contrapartida, conteúdos como produtos notáveis, matrizes e vários outros conteúdos, estão poucos estão contextualizados nos livros didáticos.

Para entender Matemática, não basta apenas abstração, temos que procurar situações do cotidiano, aproximando os conhecimentos adquiridos com criatividade e relacionando-os a um contexto. Assim, a contextualização na docência da Matemática é um tema presente nas discussões nos Parâmetros Curriculares Nacionais (PCN) e nas diretrizes curriculares.

Entretanto, esses conceitos têm-se tornado objeto de equívocos/polêmicas na problematização de situações para os estudantes, segundo Almouloud (2014), alguns professores e autores de livros didáticos propõem contextos de ensino que compreendem apenas aspectos utilitários do cotidiano. Isto, faz pobre o conceito da contextualização, conduzindo a atenuação dos processos de aprendizagem e de ensino de conceitos matemáticos.

Saber Matemática é identificar teoremas e noções enquanto elementos de um corpus socialmente e cientificamente reconhecido. É também formular definições e enunciados dessas informações e demonstrá-las. Segundo Douady (1994), as noções 
e teoremas têm atualmente status de objeto, sendo estes despersonalizados, descontextualizados e atemporais.

Neste sentindo, ensinar a disciplina de Matemática é produzir as condições necessárias à produção de conhecimento para os discentes e apreender Matemática é se submergir em uma atividade cuja consequência é a disponibilidade de um conhecimento com seu duplo status, o de ferramenta e de objeto.

Para que realmente haja ensino e aprendizagem, é necessário que o saber seja um objeto importante e essencial para as interações entre o educador e a classe, e que esse saber seja uma aposta importante para as instituições de ensino. Almouloud (2014) relatam que muitas vezes, pode parecer que certas coisas que estudamos em Matemática não têm uma aplicação imediata em nossa vida. Isso, talvez deixe o estudante um pouco desapontado, causando o desinteresse pela disciplina, porém é fácil perceber a contextualização em conteúdos como: juros, porcentagens, trigonometria e geometria. Outros, no entanto não são de fácil contextualização (ex.: dízimas periódicas, logaritmos e matrizes).

A contextualização nos livros didáticos nem sempre dá suporte ao docente na busca da consolidação do processo ensino-aprendizagem, ficando, assim, o professor incumbido de tal tarefa. Isto não significa, que o docente, em seu exercício pedagógico, tenha que contextualizar todos os conteúdos abordados, pois, além de ser uma tarefa difícil, o mesmo não detém tempo suficiente devido às altas cargas horárias enfrentadas praticamente por todos. Por isso, deve-se estabelecer critérios de acordo com a necessidade dos educandos, inclusive aproveitando o meio circundante no qual a instituição está inserida (zona rural ou urbana, centro ou periferia, etc.), ou seja, o ensino deve ser útil para o aluno.

Vale ressaltar, que a contextualização na prática pedagógica é uma ferramenta importante na consolidação do ensino-aprendizagem, buscando identificar, e posteriormente aplicar procedimentos metodológicos que aproximem conteúdos da área que, a princípio, não estão relacionados com o dia-a-dia dos estudantes. 
Assim o presente artigo objetou-se analisar o ato de contextualização na docência da Matemática. A estrutura do presente artigo tratando-se de um estudo do tipo bibliográfico, utilizando livros, artigos, monografias e manuais. A pesquisa bibliográfica segundo Marconi e Lakatos (2012) é o levantamento de toda a bibliografia já publicada, em publicações avulsas, livros, revistas e imprensa escrita. O seu objetivo é de fazer com que os pesquisadores fiquem em contato com todo o material sobre um determinado tema, auxiliando-o na análise ou na manipulação de suas pesquisas.

\section{AS CONTRIBUIÇÕES DA CONTEXTUALIZAÇÃO}

De modo frequente, usa-se a termologia contexto para referir-se a uma dada situação. Assim, conhecer um contexto, significa ter as melhores condições de apropriar-se de um determinado conhecimento ou de uma informação. O Ministério da Educação (2006), coloca a interdisciplinaridade como fundamento curricular dos Parâmetros Curriculares Nacionais (PCN), sendo capaz de gerar uma revolução no ensino. Basicamente, a ideia seria formar indivíduos que se realizem enquanto profissionais e cidadãos, exigindo, da escola mais do que o simples acúmulo de informações. Para tanto, exigem-se experiências diversificadas e concretas, transpostas da vida cotidiana dos indivíduos para as distintas situações de aprendizagem (BRASIL, 2006).

Segundo os PCNs (1997a), a contextualização do ensino tem como basilar característica o fato de que qualquer conhecimento compreende uma conexão entre sujeito/objeto. Assim, quando constrói o conhecimento de forma contextualizado, a instituição (escola) está retirando o educando do seu estado de expectador passivo.

Preconizada pelos PCNs, a aprendizagem contextualizada busca que o aluno aprenda a movimentar determinadas competências para resolver problemas com contextos apropriados, de forma a ser capaz de contemporizar essa capacidade para os contextos do mundo social, especialmente do mundo produtivo. Sobretudo, a contextualização se constrói na percepção da formação de performances que serão analisados nos exames e nos processos de trabalho. 
Assim, Tufano (2001) relata que contextualizar é a ação de colocar no contexto, colocar algo a par de determinada coisa. Trata-se, pois, de um ato premeditado, para situar um sujeito no espaço e no tempo desejado. O autor, ressalta que a contextualização pode ainda ser entendida como uma argumentação ou uma maneira de encadear ideias.

Colaborando com autor supracitado, Fonseca (1995) coloca que a contextualização não significa abolir a técnica, mas ultrapassar e entender variáveis externas, onde, os conteúdos possam ser compreendidos dentro de um panorama social, histórico e cultural que o compuseram.

Na matemática, a contextualização é um instrumento útil, desde que o mesmo seja entendido em uma abordagem ampla e não colocada de forma artificial, e que forçada, não se limita apenas ao dia a dia do discente. Assim, é preciso entender a reflexão de que a contextualização instiga a capacidade criadora, a curiosidade e o espírito inventivo do aluno.

Para Pires e Arndt (2014), as linhas de vanguarda da educação da Matemática brasileira têm atualmente um cuidado cada vez maior com os aspectos socioculturais de sua abordagem. Os autores supracitados destacam, o imperativo da contextualização e do conhecimento matemático a ser passado, procurando suas origens, acompanhando a evolução, explicitando a finalidade ou o papel na transformação e na interpretação da realidade do aluno. É nítido que não se quer negar o valor da compreensão, nem postergar a aquisição de metodologias, mas expandir a repercussão que o aprendizado de determinada percepção possa a vim a ter na vida social, nas opções, na produção de quem aprende.

Neste sentindo, os mesmos autores destacam que, com uma educação contextualizada, o educando tem maiores possibilidades de entender os ensejos pelos quais estuda determinado conteúdo. Ideia análoga a essa é a de D’Ambrósio (2005, p. 6):

Contextualizar a Matemática é fundamental para todos. Afinal, como podemos deixar de relacionar a adoção da numeração indo-arábica na 
Europa com o florescimento do mercantilismo nos séculos XIV e XV? Ou Os Elementos de Euclides com o panorama cultural da Grécia Antiga? E não se pode entender Newton descontextualizado. \{...\} Alguns dirão que a contextualização não é importante, que o importante é reconhecer a Matemática como a manifestação mais nobre do pensamento e da inteligência humana... e assim justificam sua importância nos currículos"

Assim, destaca-se a importância de relacionar os diversos assuntos, pois o importante, é a escola ter como objetivo que o aluno avalie, não esquecendo dos fatores envolvidos nesse processo, visto que, conforme afirmam os PCN (1997b, p. 7):

O conhecimento formalizado da matemática necessita ser passado para tornar-se possível de ser aprendido, ensinado; ou seja, os pensamentos dos teóricos matemáticos não são passíveis de comunicação direta ao aluno. (...) Esse processo de transformação do conhecimento científico em conhecimento escolar não passa só por mudanças de natureza epistemológica, contudo é influenciado por condições de ordem cultural, social e que procedem na elaboração de saberes intermediários, como ajuntamentos provisórios, cogentes e intelectualmente formadoras. É o que pode chamar de contextualização do saber.

$\mathrm{Na}$ atualidade, pode-se perceber que existe uma aversão dos educandos em acerca da Matemática e isso, diversas vezes dá-se porque as matérias de Matemática são apresentadas de uma forma abstrusa de ser compreendida. É imprescindível ressaltar, determinados aspectos e críticas que são colocadas à docência para então compreender o que almeja com a contextualização da Matemática atualmente.

Para Santos (2010), a insatisfação expõe que há dificuldades que carecem ser encaradas, como a carência de mudar o ensino. Há urgência em rever os conteúdos e reformular os objetivos, buscando metodologias compatíveis com a formação que atualmente a sociedade reclama. $\mathrm{O}$ autor ainda ressalta, os problemas oriundos do ensino tradicional: como a inópia de significado, a valorização de uma memorização sem compreensão e os procedimentos mecânicos. 


\section{A NECESSIDADE DA CONTEXTUALIZAÇÃO}

No atual contexto educacional, a discussão da necessidade da contextualização está presente nas alocuções dos profissionais de educação, que intuem a dificuldade de contextualizar, provocando, assim, o desenvolvimento de aulas que busquem uma abordagem ampla do conteúdo, englobando suas inserções econômicas, políticas, culturais e sociais.

$\mathrm{Na}$ visão de Lobato (2008), a educação atual permite diversos pontos de debate, inclusive o que é lecionado nas escolas. Segundo o autor, os críticos da área discutem a estagnação da educação, afirmando que, com o transcorrer dos anos aconteceram poucas mudanças significativas, especialmente na forma como o conteúdo lecionado. Neste sentindo, segundo o autor supramencionado, os professores, muitas vezes, ficam refém dos currículos rígidos ou pelo material didático fechado, que a grande parte das escolas possui, acabando por esquecer o papel que o professor tem na formação dos alunos.

Sabe-se, que o discente só estará motivado para os estudos quando o assunto trabalhado em aula despertar o seu interesse. Dessa forma, ele verá na sua aprendizagem o contentamento de sua precisão de conhecimento. Uma das variáveis de crítica à escola, para Ricardo (2003) é a crônica de o ensino tradicional não levar em conta interesses da vida do aluno. Essa separação escola/vida faz com que o aluno perca interesse pelo que é ensinado. Pensando nisso, a LDB 9.394/96, no artigo $28^{\circ}$ determina que:

os sistemas de ensino promoverão as adaptações necessárias à sua adequação às peculiaridades da vida rural e de cada região, especialmente: I - conteúdos curriculares e metodologias apropriadas às reais necessidades e interesses dos alunos da zona rural; II organização escolar própria, incluindo adequação do calendário escolar às fases do ciclo agrícola e às condições climáticas; III - adequação à natureza do trabalho na zona rural (Lei no 9.394 de 20 de Dezembro de 1996. Art. 28)

Assim, os sistemas de ensino promoverão as adaptações imprescindíveis ao seu ajustamento às características de cada região. Isso propaga que a docência carece 
levar em conta o dia a dia, a realidade, as experiências vividas pelos alunos de cada região, enfim, ensinar conforme o contexto dos estudantes.

Neste sentido, Campos (2008) afirma que somente baseado nisto, é que o informação ganhará sentido para o discente, do contrário, ele poderia se perguntar: "Qual o motivo para estar estudando isso?" ou "Quando eu vou usa isso?" questionamentos que poderão fazer com que o estudante comece a rejeitar a disciplina, dificultando, assim, o processo de aprendizagem.

Para que isso não advenha e o discente sinta gosto e prazer pelo conhecimento, o professor necessita definir o tratamento a ser realizado no conteúdo que será ensinado e, posteriormente, tomar as decisões metodológicas e didáticas para que a atmosfera de aprendizagem seja eficaz.

O pensamento da contextualização obsecra, em muitos casos, a intervenção do aluno em todo o seu processo de aprendizagem, produzindo conexões entre os vários conhecimentos. Dessa forma, o estudante será mais do que apenas um espectador, passando a ser o protagonista; como um ator que pode mudar e resolver os problemas tanto de si mesmo, quanto do mundo ao seu redor.

Para tal, é preciso que o professor invente situações comuns e que faça o aluno interagir ativamente de modo afetivo e intelectual, trazendo o cotidiano e aproximando dos alunos. Para Lobato (2008), isso é sempre possível, pois as experiências e os campos são praticamente inesgotáveis, podendo ser utilizados para dar significado e vida ao conhecimento.

A contextualização pode dar razão àquilo que o discente aprende, fazendo a ligação do que está sendo ensinado com a experiência cotidiana. Por meio da contextualização, o discente faz uma ponte entre teoria/prática, o que é relatado nos Parâmetros Curriculares Nacionais. Assim, a contextualização curricular é imprescindível para motivar os alunos. Logo, se o educador, conseguir aproximar para a sala situações que permitam ao educando identificar-se, haverá uma maior interação em sala, pois, segundo Palma et al. (2010) vê-se, uma ligação direta com 
sua vida. Neste aspecto, a instituição deve colaborar para a formação do discente, vendo-o como individuo humano, crítico e reflexivo frente à sua realidade. Dessa forma, as várias estratégias de ensino precisam permitir o sentido da aprendizagem, e a contextualização apresenta-se como possibilidade de dinamizar a docência, seduzindo mais o discente com o conhecimento científico, implantado no seu mundo de vida.

Lobato (2008), no entanto, afirma que a contextualização é uma utopia na maioria das escolas, pois, em grande parte das vezes, o docente acaba por conhecer suas turmas com uma/duas semanas antes do início das aulas, perdendo, neste caso, a oportunidade de incorporar materiais atraentes e interessantes para essas turmas. Para o autor, o programa de cada componente curricular não deveria ser um embrulho fechado, mas sim aberto, onde no curso das aulas, o mesmo pudesse interagir com os discentes a fim de conhecê-los profundamente.

Segundo Marangon (2003), atualmente, a convivência entre aluno e professor na sala mostra que o ensino está desligado da vida real do aluno. Parece que o docente, ao entrar na sala de aula, acaba esquecendo de todo o restante do mundo: da globalização, as injustiças sociais, os conflitos mundiais, é como se as divisórias da sala impedissem a entrada de objetos não preditos pelos programas adotados pela escola. Para o autor esse programa precisa ser repensado, pois:

Só quando o professor sai da disciplina e consegue contextualizar é que o aluno vê uma ligação com a vida, ou ainda, se o conteúdo trabalhado na sala de aula tiver relação com a vida do educando, o êxito será maior mas, para isso é necessário, construir uma ponte entre o mundo real, ou seja, uma ponte entre as sociedades modernas em constante transformação, e o mundo da escolar, que tem diante de si a missão de formar cidadãos (MARANGON, 2003, p. 22).

O que propõe o autor acima saísse realmente do papel, se fosse realmente colocado em prática, certamente não haveria o porquê de nutrirmos a indústria dos livros didáticos e tantas outras políticas incrustadas no âmbito escolar. Mas, para sair de fato do papel, seria preciso que educadores e educandos estipulassem objetivos e metas a serem obtidas no decorrer, como preconizam Demo (2012) e Thiollent (2007), 
porque não se almeja que as aulas nasçam do nada. É preciso um roteiro nítido em concordância com o que acontece além dos portões da instituição.

Paulo Freire (2008) insiste que o conhecimento é resultado de um arrolamento dialético que se constitui entre educando e educador, na qual os dois têm o que aprender. Entretanto, aprender com o discente não quer dizer que o educador deve deixa que a turma realize tudo e o mesmo apenas avalie, mas sim, denota que aprender significa respeito, troca e valorização da participação pessoal do educando.

Nesse processo, podem ser colocados aspectos como: problemas socioeconômicos, físicos, culturais, ambientais, políticos, etc. Não carecem estar ligados de forma direta aos alunos, mas podem fazer alusão aos seus familiares e contexto, desde que os mesmos estejam envolvidos com a conjuntura apresentada.

\section{A CONTEXTUALIZAÇÃO NA PRÁTICA DA SALA DE AULA}

A educação é um processo integralizado de socialização dos indivíduos e, tem sido abordada de diferentes maneiras, na sociedade brasileira. Dessa forma hoje, o ensino adquiriu um tom de que, qualquer conteúdo a ser estudado, deve ter analogia com a vida dos discentes. Entretanto os professores, ao formular atividades e exercícios que não contemplam a realidade, fazem com que discente se torne em indivíduos ensinados exclusivamente em armazenar termos, repetir conceitos e empregar fórmulas, sem reconhecer as possibilidades de associá-los a seu dia a dia.

No exercício da docência professores estão sempre confortando-se desafios na trajetória de encontrar ferramentas que facilitem aos alunos a apropriação dos conhecimentos e que são expostos no conteúdo da grade escolar. A aprendizagem assim, é um processo complexo e quanto mais o professor adquirir a consciência dessa complexidade, mais fácil encontrará os procedimentos melhores para promover esse processo e conseguir resultados satisfatórios. 


\subsection{A INTERDISCIPLINARIDADE DOS CONTEÚDOS E AS ATIVIDADES DE CAMPO VOLTADAS AO ESTUDO DA MATEMÁTICA}

A Matemática que é hoje utilizada é resultado de um processo que levou vários séculos para sistematizá-la e que a grande parte dos professores trabalham com ela como se fosse produto acabado e pronto, desvinculando-a de um processo social. Destarte, não existe reflexão na maneira como a Matemática é ensinada, ela foi arquitetada pelo individuo ao longo do tempo e impulsionada pela sociedade buscando prover as necessidades do homem.

Segundo Fossa (2001), a História da matemática é um dos teores de se contextualizar o seu ensino, enquanto possibilidades de estabelecer o conhecimento no espaço e no tempo, bem como despertar os alunos para a aprendizagem da Matemática.

A contextualização da matemática em conteúdos de outras áreas é uma outra fermenta de mostrar a contribuição, na leitura dos vários fenômenos sociais e naturais em que outras ciências apresentam. A interdisciplinaridade nesse caso, consiste em empregar os conhecimentos para deliberar um problema ou entender um acontecimento sob outra visão.

Zaslavsky (2009) destaca que muitas vezes o docente tem a dificuldade de discorrer sobre um determinado conteúdo matemático, por ser muito abstrato para o aluno. Neste caso, o educador pode recorrer ao contexto proativo, isto é, desenvolver o raciocínio do discente, a partir de um conceito mais elementar, daquele conhecimento, ou valer-se de uma construção de um pensamento elementar para atingir, uma outra estrutura mais elevada, sendo está uma outra maneira de contextualização.

Da mesma maneira, pode-se situar um conhecimento matemático mais elevado através da manipulação de um dos conceitos simplistas e conhecidos pelo discente, a partir de um conteúdo mais complexo, pode-se melhorar o entendimento de outro já conhecido. Destarte esta maneira de contextualização permite ao educador justificar um conteúdo buscando à motivação do discente para o estudo. 
Observa-se, que existem vários jeitos de contextualizar e que o docente pode utilizálas de maneiras variadas. Para Lopes e Frant (2011) professores que relatam utilizar a contextualização percebem, que os discentes, têm aversão à Matemática, sendo este um repto e uma das causas que mais os levam a confiar que a contextualização é uma maneira de acabar as dificuldades, permitindo que eles apreciem a Matemática.

Segundo os autores supramencionados, por meio da contextualização, a Matemática se apresenta mais aplicável na realidade, possibilitando maior entendimento por parte dos educandos. No entanto, os professores acreditam que trabalhar no dia a dia não é suficiente e depende do contexto do qual os alunos estão, o que leva muitos a utilizarem a história da Matemática, contudo, não reconhecem que a mesma é um meio de contextualizar.

Lopes (2005) destaca que alguns professores expõem a ideia de que a contextualização é falha, pois nem tudo é possível de aplicações no cotidiano e em muitos casos a persistência na aplicação em sala compromete a qualidade do ensino. Alguns alegam que inovar é uma tarefa difícil, exigindo muito trabalho, o que é desestimulante para os mesmos e ainda, sentem-se pouco amparados para empregar a contextualização, pois aprenderam a Matemática fora de um contexto e mesmo hoje, a aplicação dos conteúdos é muito pouco explorada. Além do mais, existe a falta materiais didáticos para subsidiar à contextualização.

É importante destacar a fala de Zaslavsky (2009) que mesmo os docentes que falam em contextualizar pouco sabem sobre contextualização, muitos desses construíram um conceito equivocado. Algum destes, adotam a contextualização como um procedimento de ensino, em que o ensino contextualizado é o que o professor deve relacionar com o conteúdo a ser trabalhado com algo da realidade do discente. Isso ocasiona em um grande problemática, pois quando usam qualquer outro tipo de contexto, pode trazer assim um conceito errôneo de contextualização, que vai se propagar no meio educacional.

Alguns professores se veem traumatizados e frustrados com contextualização porque na graduação, tiveram professores, que não utilizavam nenhum recurso motivador. 
Dessa forma, os conteúdos se apresentavam complexos o que, dificultava o aprendizado, levando a alguns a perderem o interesse pelo curso, mas alguns reconhecem que muito aprenderam à sua maneira, ou seja, arquitetado pelo próprio discente.

Nesse sentido, é preciso trabalhar com elaborados contextos, usando todas as áreas dos saberes, não deixando as aulas serem monótonas, podendo fazer algo diferente para melhora-las, pois os conteúdos já prontos não possibilitam a devida interação com as outras áreas do saber, assim é possível envolver os discentes relacionando a temas da aula.

\subsection{A INTERDISCIPLINARIDADE COM A FÍSICA}

A ciência física em seus estudos busca explicar e entender a ocorrência dos mais variados fenômenos naturais que acontecem diariamente, no entanto, ela, assim como as outras ciências, não trabalha sozinha. A física relaciona-se com outras ciências, entre elas matemática e a química e, entretanto, há entre a matemática e a física uma relação de proximidade maior, que possibilita dizer que a física não existiria sem a matemática. É possível visualizar a relação de interdisciplinaridade que existe entre elas. Isso fica evidente para os discentes, especialmente para àqueles que começam o estudo da física, a partir do momento que é dada para a resolução de problemas, momento no qual é necessária a relação das teorias com a aplicação da matemática.

Segundo Galileu Galilei (1642) citado por Mariconda e Lacey (2001), a matemática é a linguagem da física, ou seja, a física necessita da matemática para possa concretizar-se. Francis Bacon (1626) diz que à medida que a física evolui ela precisa de um auxílio, um instrumento para que possa concretizar os conceitos e suas teorias, nesse aspecto que a matemática tem sempre uma ferramenta pronta e disponível.

Ao longo da história da física, muitos dos cientistas contribuíram para a descoberta e evolução de conhecimentos eram a priori matemáticos, alguns deles criaram ferramentas matemáticas, para os que necessitavam descrever a ocorrência de 
fenômenos. Isaac Newton (1727) foi um desses cientistas. Ele criou, o cálculo diferencial, de modo a descrever os movimentos que os corpos realizavam.

$\mathrm{Na}$ matemática estão contidos milhares de instrumentos que possibilitam à física descrever e compreender fenômenos que acontecem corriqueiramente ao nosso redor. Matemática e Física são ciências que estão ligadas uma na outra e não vivem isoladamente, necessitando uma da outra para explicar e descobrir os fenômenos que ocorrem na natureza.

Assim destaca-se abaixo o quadro 1, um compilado com os temas mais relacionados:

Quadro 1: Assuntos de Física e a Interdisplinaridade

\begin{tabular}{|l|l|}
\hline $\begin{array}{l}\text { Assunto } \\
\text { cinemática: movimentos retilíneos e }\end{array}$ & $\begin{array}{l}\text { Interdisciplinaridade } \\
\text { É comum a cobrança de questões } \\
\text { envolvendo a velocidade média e o uso } \\
\text { de gráficos. }\end{array}$ \\
\hline $\begin{array}{l}\text { Dinâmica: movimentos retilíneo e } \\
\text { curvilíneo }\end{array}$ & $\begin{array}{l}\text { Exigem a determinação do resultante de } \\
\text { forças ou a decomposição delas. }\end{array}$ \\
\hline Trabalho e energia & $\begin{array}{l}\text { Sistemas mecânicos que exigem a } \\
\text { utilização dos conceitos de energia, bem } \\
\text { como sua conservação ou dissipação. }\end{array}$ \\
\hline Calor e fenômenos térmicos & $\begin{array}{l}\text { Em termometria, é cobrada a conversão } \\
\text { entre as unidades de efeitos e } \\
\text { temperatura. }\end{array}$ \\
\hline
\end{tabular}

Fonte: Elaborado pelo próprio autor.

A teorias da física encerram, em geral em muita matemática. Como foi mostrado no quadro 1, todos esses temas entre a física e a matemática são fácies de contextualizar, pois tem muito a ver com o dia a dia do aluno. Desse modo, os professores podem cair movimentos de objetivos, carros, situações como parque de diversões para ensinar conteúdos considerados chatos pelos alunos. 
Para Santarosa (2013) há entre a Física e a Matemática uma relação de proximidade, pode-se mesmo dizer de intimidade. A Física, conhecimento do mundo material não se pode fazer sem a Matemática. A linguagem da Física é, sem nenhuma dúvida, a Matemática. Destarte quem não souber matemática nunca poderá entender a Física, muito menos os seus princípios. A maneira sucinta, elegante e clara de exprimir as leis da física, os enunciados do comportamento do mundo material é a própria Matemática. Mas, além disso, a Matemática é por outro lado, a maneira de retirar, sem erros, as consequências das leis. Conforme o alemão Wilhelm Roentgen (1923), "O físico precisa de três coisas para seu trabalho: matemática, matemática e matemática".

Não faz o menor sentido colocar Física e Matemática como disciplinas distantes. Pior que isso, como disciplinas sem conexão e distantes. Felizmente, nos últimos anos essa tendência está sendo revertida, levando cada vez mais uma interdisplinaridade entre a Matemática e a Física

\subsection{A INTERDISCIPLINARIDADE COM AS OUTRAS ÁREAS DO SABERES}

Situações e ideias de natureza matemática fazem presentes nas coisas cotidianas como já foi relatado, nas práticas de distintas culturas, nas atividades profissionais, em situações de medição, cálculo e contagem, que são reconhecidas como Matemáticas, mas ainda em outras que compreendem processos de localização, classificação, explicação, representação, planejamento e organização em atividades como brincadeiras e jogos.

É fácil reconhecer em nossa sociedade, o valor e a presença da matemática que, além de universal é obrigatório. A matemática faz parte em todos os países dos currículos escolares, não importando a cultura ou nível de desenvolvimentos econômico e social. Não a menor dúvida sobre a importância de ensinar matemática nas escolas, há muita discussão sobre como ensiná-la e principalmente como contextualiza-la com as outras áreas dos saberes. 
Segundo D'Ambrosio (2002) os motivos que justificam porquê o ensino da Matemática nas escolas são pela utilidade enquanto instrumentador para a vida; por ser parte das raízes culturais; por ajudar a pensar e a raciocinar melhor; por ser útil como instrumentador de trabalho; por sua construção formal e lógica.

Porém, a Matemática tem níveis e aspectos de complexidade que é preciso considerar quando organizamos seu o ensino, passando das atividades às aplicações práticas, sem esquecer que é uma ciência abstrata e, deve ser tratada na conjuntura adequada, respeitando o desenvolvimento cognitivo dos alunos.

Para envolver os alunos nas situações de práticas matemáticas, segundo Santarosa (2013) o educador precisa optar por aquilo que é imediatamente próximo, sensível, significativo e familiar: suas experiências pessoais (suas brincadeiras, vivências, habilidades), seu meio social (colegas, familiares, professores) e seu entorno (sua rua, sua casa, sua comunidade, sua cidade) em síntese a sua realidade (GROENWALD; FILIPPSEN, 2003).

Uma consequência automática do envolvimento dos alunos com os contextos significativos é o valor da resolução de problemas, onde para muitos educadores precisa ser o foco do currículo de Matemática. O que se aconselha aos professores é que busquem investigar e explorar os contextos a partir dos próprios seus alunos, de suas experiências e da sua cultura.

É quase impossível listar todos os contextos possíveis que podem ser problematizados e explorados na Matemática. Assim baseado no quadro 2 que se visualiza às condições locais que pode dar ideias e inspirar aos educadores para ensinar os conceitos e os procedimentos, organizando uma sequência didática. 
Quadro 2: Contextos, Situações Problema e Conteúdos

\begin{tabular}{|l|l|l|}
\hline \multicolumn{1}{|c|}{ Contexto } & \multicolumn{1}{|c|}{ Situação-problema } & \multicolumn{1}{c|}{ Conteúdos } \\
\hline Meu corpo & $\begin{array}{l}\text { Agrupamentos, contagens nos } \\
\text { dedos, medidas com o corpo, } \\
\text { simetrias. }\end{array}$ & $\begin{array}{l}\text { Contagens, agrupamentos (5 } \\
\text { em 5,10 em 10), medidas não } \\
\text { convencionais, simetria, etc. }\end{array}$ \\
\hline Minhas coisas & $\begin{array}{l}\text { Contagem e comparação de } \\
\text { figurinhas, bolinhas de gude, } \\
\text { bonecos, objetos pessoais } \\
\text { (vestimenta, higiene, etc.). }\end{array}$ & $\begin{array}{l}\text { Classificação, formas 2D e 3D, } \\
\text { contagens, medidas. }\end{array}$ \\
\hline Família & $\begin{array}{l}\text { Aniversários, jogos com nomes } \\
\text { e idades. }\end{array}$ & $\begin{array}{l}\text { Classificação, operações básicas, } \\
\text { comparação, contagens, } \\
\text { agrupamentos. }\end{array}$ \\
\hline A casa & $\begin{array}{l}\text { Organização da mesa para o } \\
\text { jantar, organização do armário, } \\
\text { esboço da planta da casa, } \\
\text { explorar sequências numéricas } \\
\text { teclando um controle remoto } \\
\text { de TV. }\end{array}$ & $\begin{array}{l}\text { Agrupamentos, classificação, } \\
\text { sequências, formas, medidas, } \\
\text { relações geométricas (ângulos, } \\
\text { paralelismo, perpendicularismo). }\end{array}$ \\
\hline
\end{tabular}

Fonte: Adaptado de Brasil (2014).

Refletindo sobre o quadro 2, se um dos objetivos é explorar os contextos significativos com os alunos, cabe então, o professor dar valor dos problemas e seu uso na escola. Entretanto para Machado (2002) os educadores utilizam pouco material auxiliar em suas aulas, usam como justificativa, a cobrança para o uso do livro por partes das instituições e dos pais, sentindo-se assim obrigados a seguir aquilo que vem nos livros e desenvolverem os temas segundo neles organizados.

Segundo o autor supracitado, ainda acreditam não poder se aprofundar os conteúdos, nem muito mesmo ir além daquilo proposto. Alguns dos professores oferecem resistência, defendendo o conceito de que a Matemática é uma ciência que exige permanente treino, e com isso gastam a maior parte das suas aulas treinando os discentes a fazerem simples contas, pois segundo os mesmos é melhor que o 
estudante aprenda pouco, mas pelo menos aprenda a fazer as contas básicas da Matemática.

Deste modo, os discentes acabam levantando uma interpretação da Matemática errônea, pois ela não apenas um conjunto de regras prontas e intocáveis, não percebendo assim como e quanto a Matemática está presente em nossas vidas, e por essa razão tomam aversão pela Matemática. Esta aversão acaba sendo repassada na cultura perpetuando-se por várias gerações, causando consequências desastrosas no ensino da Matemática.

\section{CONSIDERAÇÕES FINAIS}

A matemática vem sendo comprometida por uma expansão e revisão das suas próprios considerações, por isso não deve-se apresentá-la como uma disciplina homogênea, fechada ou desconexa da realidade, e sim tentar auxiliar no processo de construção do saber, e por consequente na aprendizagem, de maneira em que a mesma se torne indispensável para o aluno.

Neste enfoque, foram relatados através dos trabalhos analisados o consenso entre os docentes e pesquisadores, que a Matemática tem sido lecionada de maneira enfadonha. É preciso criar um método que desperte o interesse dos discentes e um enfoque do professor em suas aulas, procurando torná-la mais interessante e dinâmica.

Observou-se, que uma das problemáticas mais enfrentadas, é o grau elevado de antipatia causada por ela, especialmente por causa da à ausência de exercícios e problemas que a relacione com o mundo real. Outro fator é que muitos professores desconhecem o real significado da contextualização e assim não sabem utilizá-la. Isto acaba refletindo diretamente no aprendizado, levando os alunos a acreditar que o docente não está ensinando nada e apenas enrolando durante as aulas.

Destarte, o objetivo de utilizar a contextualização, é de poder criar cenários para uma aprendizagem motivadora, que supere o distanciamento entre as experiências do 
aluno e os conteúdos estudados, estabelecendo relações e trazendo alusões que podem ser de natureza sociocultural ou histórica ou mesmo na própria Matemática.

Alcançar interdisciplinaridade entre os conteúdos e a Matemática, proporcionando ao aluno a oportunidade de observar a utilidade e suas várias aplicações, e com isso pudemos perceber a evolução do interesse dos alunos pela disciplina.

\section{REFERÊNCIAS}

ALMOULOUD, S. A. Contexto e contextualização nos processos de ensino e aprendizagem da Matemática. Brincando e Aprendendo Matemática. Blogspot, 2014.

Disponível

em:

http://brincaprendematematica.blogspot.com.br/2014/10/contexto-e-

contextualizacaonos.html. Acesso em agosto de 2020.

BRASIL. Pacto Nacional pela Alfabetização na Idade Certa: Saberes Matemáticos e Outros Campos do Saber / Ministério da Educação, Secretaria de Educação Básica, Diretoria de Apoio à Gestão Educacional. - Brasília: MEC, SEB, 2014.

BRASIL. Ensaios pedagógicos. Brasília: Ministério da Educação, Secretaria de Educação Especial, 2006.

BRASIL. Parâmetros Curriculares Nacionais. Apresentação - versão agosto/1996.

BRASIL. Parâmetros Curriculares Nacionais: introdução aos Parâmetros Curriculares Nacionais. Brasília: MEC/SEF, 1998.

BRASIL. Secretaria de Educação Fundamental. Parâmetros Curriculares Nacionais: introdução aos parâmetros curriculares nacionais. Brasília: MEC/SEF, 1997a.

BRASIL. Secretaria de Educação Fundamental. Parâmetros curriculares nacionais: matemática. Brasília: MEC/SEF, 1997b. 
CAMPOS, M. T. R. A. Materiais Didáticos e Formação do Professor. Consultoria da Secretaria de Educação do Estado de São Paulo, 2008.

D’AMBRÓSIO, U. Sociedade, cultura, matemática e seu ensino. Em foco: educação matemática em perspectiva. Educ. Pesqui, V. 31 n.1, São Paulo Jan./Mar. 2005.

DEMO, P. Pesquisa participante: Saber pensar e intervir. Brasília: Líber Livro, 2014.

DOUADY, R. Engenharia Didática e Evolução em relação ao conhecimento: Aritmética crônica mental, álgebra para um projeto na faculdade conjunta. Benchmarks IREM No.15, Edições abril tópicos, 1994.

FONSECA, M. C. F. R. Por que ensinar Matemática. Presença Pedagógica, Belo Horizonte, v.1, n. 6, mar/abril, 1995.

FOSSA, J. A. Ensaios sobre a Educação Matemática. Belém: EDUEPA, 2001.

FREIRE, P. Pedagogia da autonomia. São Paulo: Editora Paz e Terra, 2008.

GROENWALD, C. L. O.; FILIPPSEN, R. M. J. O meio ambiente e a sala de aula. Educação Matemática em Revista. (SBME), v, 22, n. 13, p. 36-40, 2003.

LOBATO, A. C. Contextualização: um conceito em debate. Educação pública. Biblioteca virtual. ISSN. 1984-6290. CECIERJ, 2008.

LOPES, A. J.; FRANT, J. B. Nós da matemática: soluções para dez desafios do professor. São Paulo: Ática Educadores, 2011.

LOPES, A. J. Explorando o uso da calculadora no ensino de matemática para jovens e adultos. In: BRASIL, Construção coletiva: contribuições à educação de jovens e adultos. Brasília: UNESCO/MEC, 2005.

MACHADO, N. J. Epistemologia e Didática: as concepções de conhecimento e inteligência e a prática docente. São Paulo: Cortez, 2002. 
MARANGON, C. Coleções ensinam matemática. Revista Nova Escola. Ed. 165, setembro, 2003, p. 48-51.

MARCONI, M. A; LAKATOS, E. M. Técnicas de Pesquisa. 7 ed. São Paulo: Atlas, 2012.

MARICONDA, P.; LACEY, H. A águia e os estorninhos: Galileu e a autonomia da ciência. Tempo soc. vol.13 no.1 São Paulo May 2001.

PALMA, et al. Educação Física e a organização curricular: educação infantil, ensino fundamental, ensino médio. 2. ed. Londrina: Eduel, 2010.

PIRES, C. M. ARNDT, M. D. Contextualizando a Matemática através da confecção de camisetas. 2o Encontro Nacional Pibid Matemática. Educação matemática para o século XXI: trajetórias e perspectivas. ISSN 2316-7785. Agosto, 2014.

SANTAROSA, M. C. P. Os lugares da Matemática na Física e suas dificuldades contextuais: Implicações para um sistema de ensino integrado. Investigações em Ensino de Ciências, v,18, n. 1, pp. 215-235, 2013.

SANTOS, C. S. Jogos de Linguagem no estudo do tratamento da informação em uma classe de EJA. (Dissertação Mestrado) Universidade Federal do Rio Grande do Sul. Instituto de Matemática Programa de Pós-Graduação em Ensino de Matemática: Porto Alegre, 2010.

THIOLLENT, M. Metodologia da pesquisa-ação. 9. ed. São Paulo: Cortez, 2007.

TUFANO, W. Contextualização. In: FAZENDA, Ivani C. Dicionário em Construção: Interdisciplinaridade. São Apulo: Cortez, 2001.

ZASLAVSKY, C. Criatividade e confiança em matemática desenvolvendo o senso numérico. São Paulo: Artmed, 2009.

Enviado: Setembro, 2020. 
Aprovado: Setembro, 2020. 